\title{
The investigation of the relationship between citizen participation and organizational citizenship behavior in the Gachsaran's municipality
}

\author{
Jalal kamran ${ }^{1,}$, Fahimeh Ariyan, ${ }^{1}$, Ehsan Amini ${ }^{1}$, Masood Zafari $^{1}$ \\ ${ }^{1}$ Department of Civil Engineering and Architecture, GACHSARAN Unit, Islamic Azad University, \\ GACHSARAN, Iran \\ *Corresponding author: The Faculty members of the Gachsaran University, jalalkamran11@yahoo.com
}

\begin{abstract}
:
This study has tried to examine the relationship between two variables as citizen participation and organizational citizenship behavior in the Gachsaran's municipality. Participation is of urban life's requirements and it is realized when the burgher has converted from individual life and with a sense of collective responsibility to citizens. In order to meet the needs of urban development and advertence to the posterity's share, therefore, we should plan the administration of the urban life's affair on the basis of a systematic pattern of planning with the meaningful, informed and voluntary participation of citizens.
\end{abstract}

Keywords: citizen participation, urban management, organizational citizenship behavior, urban development. 


\section{Introduction}

In the new era of increasing development of societies, the concept of partnership has developed to all participating's arenas in an open society based on the social life's personal decisions (Popper, 1369, 102).

Despite the participation's idea which has been taken place consciously and voluntarily, this issue has not been emerged, yet. The social - cultural, managerial, statutory - Legal, spatial - physical factors are of its obstacles.

Despite the fact that the citizen's participation in urban planning has dated back to Greece and medieval times, but in the term of the theory goes, this term has been stated by Smith (1973) for the first time and argued that the people and the relationships are important for planners because they can provide the necessary information and judgments of the local environment (klimowa, 2010:11).

Participation is of urban life's requirements and it is realized when the burgher has converted from individual life and with a sense of collective responsibility to citizens (Piran, 1374: 132). In order to meet the needs of urban development and advertence to the posterity's share, therefore, we should plan the administration of the urban life's affair on the basis of a systematic pattern of planning with the meaningful, informed and voluntary participation of citizens.

The society of Iran has a special feature in the field of citizen's participation that providing the pattern of urban management planning will not be useful without knowing them. From the perspective of some scholars (Piran, 1376), Social participation has a rooted contradictions for various historical and cultural reasons that suggest that Iranians were hardly been participatory in the informal and private arenas, but are not participatory in the formal arenas.

This point have been made the technical and professional meaning of the social partnership with the characteristics of voluntarily, purposefulness of the freedom of choice complicated.

This complexity has indicated the aspects and requirements that must be identified in designing the pattern of urban management planning in the spatial, physical, and structural and socio - cultural and others areas.

All of the manager endeavor in the bureaucratic system have been toward gaining greater efficiency by preserving organization's pyramidal hierarchy. Superficial and unreliable relations between individuals have been created for this reason. In such an environment, the organization and its members are given opportunity to work for the success of their organization as much as their power. Therefore, advertence to the citizens are rising in the democratic values system. Concurrently that the importance of the citizens have been perceived as so important organization's source, their behavior could be considered very important and that's why many researchers have analyzed the citizens' behavior.

In general, the citizenship's behavior is a precious and useful kind of behavior that people are blurting optional and voluntary of themselves. The terms of Organizational citizenship's behavior was first presented by Bateman and Organ in the early 1980's to the world of science.

The primary studies that was conducted in the field of Organizational citizenship behavior $^{1}$ was more at identifying the employees responsibilities or behaviors that have in the organization but often was ignored. This behavior were measured incompletely despite the traditional evaluation of job performance and sometimes were neglected, but were effective in improving organizational effectiveness. (Bienstock \& et.al, 2003, p360).

In general those behavior have been considered in the Organizational citizenship behavior that although it is not mandatory to carry out from the organization, the benefits are caused in the shadows of the employee's performance. Organ is also believed that the Organizational citizenship behavior is the individual and voluntary behavior organization which was not designed directly through the official system of bonuses, but

\footnotetext{
1 -OCB: Organizational citizenship's behavior
} 
nevertheless have been caused the improvement of the organization's effectiveness and efficiency (cohen and Kol, 2004, 386).

\section{The necessity and importance of citizenship behavior}

The city was proposed as a source of development and urban management positions has a very crucial and decisive role in the process of urban development and improvement of urban settlements. From another perspective urban management can be considered in the course of a lawful and sustainable development. This case is important from this point that the way of management on desirable urban living's flow can play the most important role in improvement of the human settlements and urban development sustainability. Because the allowed and regulators factors of the urban program derives from the efficiency of urban management (Shiee, 1382, 38).

Therefore the damages of the absence of meaningful participation in urban management planning will be more manifested with socio-cultural diversity, complex structures and specific communications, particularly in mega polis of Tehran.

The need to reduce the damages and creating an environment with citizen's comfort made the attention to the dimensions and angles of the participation necessary. The Analyze of strengths, weaknesses, opportunities and threats points of citizen participation are important thence:

1) To identify the existing strengths points and reinforce them.

2) To identify the weaknesses points and turn them into strengths.

3) To identify the threats and turn them into opportunities. Design, implementation, conservation and efficiency patterns of the urban management planning have manifested at the result of the favorable impact (Razavi Alhashem and Mosaiee, 1388: 167).
The concept of organizations' citizenship is also one of the major issues in the field of organizational behavior that tries to take an effective steps by providing the specific strategies to increase organizational commitment, performance improvement, customer satisfaction, customer loyalty and job satisfaction and so on ....

Therefore, the advertence to the citizens are increasing and their importance have perceived as a so significant source of organization and staff's behavior of staff is considered very important. That is why, todays many researchers have to analyze the citizenship's behavior in organizations. In general, citizenship's behavior is a precious and useful kind of behavior that people will blurt it as arbitrary and voluntary behavior.

Most of the conducted study on organizational citizenship behavior in our country have allocated to the concept and dimensions of organizational citizenship behavior and its causer factors and it has been less studied quantitatively and the necessity of doing such study are increased by this fact (Liu, 2008: 13).

Most of the conducted study on organizational citizenship behavior in our country have allocated to the concept and dimensions of organizational citizenship behavior and its causer factors and it has been less studied quantitatively.

\section{General and special purpose:}

Investigating the relationship between people's participation and organizational citizenship behavior.

\section{Secondary objectives:}

Investigating the relationship between subjective dimension and organizational citizenship behavior.

Investigating the relationship between the objective dimension and organizational citizenship behavior.

Investigating the relationship between Willingness to partnership and organizational citizenship behavior.

Investigating the relationship between attitude to partnership and organizational citizenship behavior. 
Investigating the relationship between participation in voluntary organizations and organizational citizenship behavior.

Investigating the relationship between social relationships and organizational citizenship behavior.

Investigating the relationship between electoral participation and organizational citizenship behavior.

\section{The study's variables:}

The study have two variables such as citizen partnership and organizational citizenship behavior.

\section{Literatures' Review:}

Rezvani and Ahmadi (1387) have conducted a study as Islamic rural councils, people's participation and rural development (Case Study: Hakim Abad village, Zarandieh city, Central Province).

The objective of this study was investigating and evaluating the bottom-up planning in order to increase local people's participation and people's effective involvement on local development affair.

In order to conduct this study, the people and council member's perspective of the performance of councils have been explored in carrying out their duties of public opinion and the people's consent of the performance of councils. The study Results indicate that the councils had a well performance in the field of the people's participation with compared to other fields such as rural economic and social situation improvement. According to the research findings, the villagers tend to participate more in different villages Affairs. So the village was in a good position by local people and council's collaboration and participation in doing rural affairs. Therefore, it is essential to make the council more strengthen because it can be an essential role in rural development.

Langroodi and Sakhaee (1388) have conducted a study entitled people's participation and rural development in the Solgi rural district, Nahavand city.In the present study, the role of public participation in the development of rural district has been studied and the case study is Solgi rural district, Nahavand city. The study has been conducted on 345 head of households in 6 villages of the Solgi rural district of city of Nahavand of Hamadan province and the documentary and survey research methods have been used by using the technique of questionnaires to determine the participation's situation in selected villages.

The conducted studies show that in addition to the potential and participations fields in rural development in the case study, There are Obstacles and the problems in four categories of economic, social, cultural and political in the way of active participation which meeting each of them requires the use of the special strategies. The mentioned sets of actions need to provide a policy and planning accordance to existence capabilities in the rural districts.

Ziyari, Zavandi, Aghajani and moghadam (1388) have conducted a study which entitled the investigation of citizen participation and its role in urban management of small cities (case study: Gale dar, Marzaneh and Hidaj cities).

In this study, three small towns of Galedar in the Fars province, Marzaneh in Isfahan and Hidaj in the Zanjan province were selected as a case study.

According to the results of the questionnaire it is determined that the intention and willingness to participate is very high in the subjective dimension and there are very appropriate attitude to participation in these cities. In the objective dimension which has measured through people's participation's factors in urban organizations and institutes, participation in recent elections and interaction with acquaintances, the people's participation are of a weak level.

Based on the obtained results of the correlation test between subjective dimension of the participation as the independent variable and people's participation, it became apparent that there are meaningful relations of subjective dimension of the participation in these cities and the context of participation in the studied cities is very high for participation in urban management.

Zakyany (1387) has been examined the strengthening of the organizational citizenship 
behavior, the role of organizational justice and organizational character in his dissertation. In this study, the five dimensions of organizational citizenship behavior have been studied base on the organ's perspective.

The obtained results of the data analysis showed that there are a positive relationship with 95 percent Confidence coefficient between organizational justice and organizational citizenship behavior and consequently the more positive perception of organizational justice in the minds of the staff the organizational citizenship behavior will be more.

Also there is a positive relationship with the same confidence coefficient between organizational justice and organizational citizenship behavior (OCB) due to the healthy personalities. It means that the impact of positive impression of staff of organizational justice on organizational citizenship behavior will be more in the organization which has a healthy organizational personality.

Baker hunt and Andress, in a study with entitled of the impacts of moral values on the incidence of organizational citizenship behavior (OCB) in 2006, came to the conclusion that organizational commitment, organizational justice and moral values have a significant impact on organizational behavior, so that the effectiveness of the organization will be high by the increase of its efficiency.

Stephan Rub has done another study in 2008 entitled Evaluation of the impact of organizational citizenship behavior on the hospitals' industrial sector in Switzerland city that by scrutinize all of the affecting factors on incidence of organizational citizenship behavior came to this conclusion that the employee who has this behavior, committed to increase the hospital's efficiency and the service's quality.

\section{Plan's Executive Profile:}

Paper type, methodology and manner of conducting the survey:

Each research choose the most appropriate method to implement base on its requirements and goals and with respect to the subject of this research, the used method is descriptive and correlational and in term of its goal, it is applied research.

\section{Data collection tool:}

The questionnaire will be used In order to collect data. To measure organizational citizenship behavior, related questionnaire on organizational citizenship behavior were responded by the heads of employees about personnel.

The reason for this is that the researchers have known the evaluation of head's employee about staff's citizenship behavior more valid. This questionnaire have been designed by using two scale of organizational citizenship behavior by MacKenzie and Podsakoff (1990) and Mayer and et al. (1997). This questionnaire are measuring four dimensions of chivalry and forgiveness (3 items), civil ethics (2 items), altruism (3 items) and conscience (4 items).

\begin{tabular}{|c|c|}
\hline Dimensiones & Studied variables \\
\hline $\begin{array}{l}\text { chivalry and } \\
\text { forgiveness } \\
\text { conscience } \\
\text { altruism } \\
\text { civil ethics }\end{array}$ & $\begin{array}{c}\text { Organizacional } \\
\text { citizenship behavior }\end{array}$ \\
\hline
\end{tabular}

Different question were designed in order to measure social participation in the subjective dimension (eight items), to measure attitudes toward participation and an independent question to measure the willingness to get involved in participation:

A) The questions involving the interest rates of respondent in relation to the neighborhood's participation of the.

B) The items have been related to: counting on the others help, the superiority of the collective decisions, inability of people to solve problems, everyone should think about himself. The importance and priority of participation in social affairs, on social affairs, on personal affairs, the utility of consult with others, the importance of the application's equality of collective and public affairs on individual affairs. 
Objective partnership: The objective and behavioral dimensions of social participation which have blurted in the form of membership, supervision, execution and decision making and include the following items:

A) Participation in voluntary organizations: the index is comprised of two sub-index such as membership and positions partnership.

- The participatory Membership: the rate and the manner of the studied subject's distribution based on the number of membership with their collaboration in institutions and groups such as: councils, parent-teacher associations, trade groups, academic groups, arts groups, religious groups and committees, sports groups and associations and charities.

Participatory position of the studied subject's status based on their participatory position in participatory community based on four categories: attendance at programs and meetings: financial assistance, intellectual assistance and executive responsibility.

B) Family and community participation Based on the relationship's rate with family members, relatives, friends and acquaintances, neighbors and local residents and Colleagues.

C) Electoral Participation in each of the four recent presidential elections, the Parliament, the City Council and the Assembly of Experts.

\section{Statistical population, sample size, methods of measurement and methods of data analysis:}

After collecting data, data extraction, data classification and frequency distribution tables and the distribution ratio tables have been prepared by researcher, a new stage of the research process which is known as data analysis phases have to begin. This phase include two analytical methods of qualitative analysis and quantitative analysis. (Hafeznia, $1385,231)$
Descriptive statistics are mainly composed of concepts such as the frequency distribution tables and distribution ratios tables, geometric representation and visual distribution, measurement of central tendency, the size of characteristics' dispersion and so on up. Descriptive statistics is used to explain the studied phenomenon or issue or subject's status or in fact the characteristics of the studied subject is described and illustrated in statistical figures (Hafeznia, 1385: 242).

In analysis of the deductive statistics this point is always considered that how the obtained results of small groups of study that called sample can be generalized to a larger groups called population. In other words, the researcher has been resorted to hypothesis test based on the obtained values in the sample and needed statistical techniques is provided through deductive statistics. In fact, data has been analyzed through two ways:

\section{1- Estimation of the population values from sample values \\ 2- The hypothesis test \\ In this study, after collecting the} questionnaires and extracting the answer in order to convert raw data into usable information from the questionnaires by using the SPSS software and logging the data to this software actions were taken to extract descriptive statistics with classified information, to convert classified information into the frequency, frequency percentage, statistical average and one and twodimensional tables.

Non-responded data were also replaced with other relevant data average and negative questions were coded again. And also modeling of structural equation and measuring the studies' model have done by using the LISREL software that we will pay to the complete and full description of this software in the following.

\section{Research limitations:}

Given to this fact that no study has been done yet, all the plan's limitation cannot be identified conclusively. But the predicted limitations for this project can be classified as follows: 
1. The lack of cooperation of the relevant organizations for the plan's needed information (Gachsaran Municipality)

2. Do not complete the project's questionnaire

3. Lack of relevant organization's authorities information and mastery to the importance of studied plan implementation.

\section{References:}

Popper, Karl (1369), “The Open Society and Its Enemies" (Translated by Ali Asghar Mohajeri), Tehran, Stock Company publication.

Piran, Parviz (1376), “conceptual and theoretical foundations of participation". Tehran, Planning Research Institute.

Pyran, Pzrviz (1374), “A comprehensive plan of public awareness: citizen-oriented. Tehran: Office of Cultural Research.

HafzNia, Mohammad reza (1380), "Introduction to Research Methods in Human Sciences", Tehran, research and development of universities Humanities Books organization (samt).

Shiee, Esmail (1382), "The need for the development of urban management in Iran", Journal of Geography and Development, pp. 37- 62.

Ziyari, Keramatolah, Zandavi.SM, Aghajani, M, Moghadam, M. (1388), "Evaluation of small-town citizenship participation and its role in urban management" (Case Study: Galeh dar, Marzaneh and Hidaj), Journal of Geography and Regional Development, No. 13, Winter and autumn 1388, pp. 211235.

Ghodsi Poor, Seyed Hassan (1381), “ The analysis hierarchy process AHP", Tehran, publication of Amir Kabir University.

Taleghani, GR, Farhangi, Ali Akbar and Abedi Jafar (1389), "designing the model of the affecting factors on the citizenship trust towards municipal administration". Journal of governmental management,
Volume 2, Issue 4, Spring-Summer 1389, pp. 89-106.

Hooman, Haider Ali (1380), "The preparation and the standardize the measurement of job satisfaction", Tehran, Public Administration Training Centre.

Bienstock, C., Demoranville, W.,\& Smith, K (2003).organizational citizenship behavior and service quality, journal of services marketing, 17 (4),357-378.

Cohen, A,. \& Kol, Y, (2004) professionalism organizational citizenship behavior : an empirical examination among Israeli nurses, journal of managerial psychology, 19.

Klimova, Zuzana. (2010).Public Participation in Urban Renewal Projects. A Chinese Perspective. International Master"s Programmer in Environmental studies and sustainability. Science (LUMES).

Liu. H.,(2008) Transcendental Leadership and organizational citizenship behavior : the mediating effect of spirituality in the workplace, Requirements for the degree of public administration. 